\title{
Hubungan Sikap, Motivasi dan Dukungan Tokoh Masyarakat Terhadap Perilaku Kepatuhan Ibu Dalam Membawa Balita Ke Posyandu
}

\author{
*Ajeng Setianingsih" ${ }^{1)}$, Dulakhir ${ }^{2)}$, Nabila Silvia Yusup ${ }^{3)}$ \\ Program studi S1 Kesehatan Masyarakat, Fakultas Kesehatan, Universitas MH Thamrin \\ Corresponden author: ajeng.alysha@ gmail.com
}

Received : 29 Desember $2020 \quad$ Accepted : 6 September $2021 \quad$ Published: 30 September 2021

DOI: https://doi.org/10.37012/jik.v13i2.435

\begin{abstract}
ABSTRAK
Posyandu merupakan salah satu upaya yang bersumber daya masyarakat, yang dilaksanakan oleh Kader Kesehatan dan telah mendapatkan pendidikan serta pelatihan. Berdasarkan hasil studi pendahuluan ditemukan 6 dari 10 ibu yang memiliki balita menyatakan tidak membawa balitanya ke Posyandu dengan alasan tidak sempat dan lupa dengan jadwal kegiatan Posyandu. Penelitian ini bertujuan untuk mengetahui hubungan sikap, motivasi dan dukungan tokoh masyarakat terhadap perilaku kepatuhan ibu dalam membawa balita ke Posyandu Edelwis I Citra Indah City Kabupaten Bogor tahun 2020. Penelitian ini merupakan penelitian kuantitatif dengan desain studi cross sectional dan analisis data secara univariat dan bivariat. Populasi dalam penelitian ini adalah ibu yang memiliki balita dan sampel penelitian berjumlah 50 responden, dengan teknik pengembilan sampel menggunakan total sampling. Berdasarkan hasil penelitian diketahui ada hubungan sikap (p-value 0,012) serta tidak ada hubungan antara motivasi (p-value 0,560$)$ dan dukungan tokoh masyarakat $(0,127)$ terhadap perilaku kepatuhan ibu dalam membawa balita ke Posyandu Edelwis I Citra Indah City Kabupaten Bogor tahun 2020. Diperlukan kerjasama antara ibu yang memiliki balita serta kader posyandu dalam hal memotivasi ibu agar mau membawa balita mereka ke Posyandu.
\end{abstract}

Kata Kunci: Sikap, Motivasi, Dukungan Tokoh Masyarakat, Perilaku Kepatuhan.

\begin{abstract}
Posyandu is one of the community-based efforts carried out by Health Cadres and has received education and training. Based on the results of the preliminary study, it was found that 6 out of 10 mothers with toddlers stated that they did not bring their children to Posyandu because they did not have time and forgot about the Posyandu activity schedule. This study aims to determine the relationship between attitudes, motivation and support of community leaders on maternal obedience behavior in bringing toddlers to Posyandu Edelwis I Citra Indah City Bogor Regency in 2020. Thisis a quantitative research withstudy design cross sectional and data analysis of univariate and bivariate. The population in this study were mothers who have children under five and the research sample was 50 respondents, with the sampling technique using total sampling. Based on the results of the study, it is known that there is an attitude relationship ( $p$-value 0.012) and there is no relationship between motivation ( $p$ value 0.560) and support from community leaders (0.127) on maternal obedience behavior in bringing toddlers to Posyandu Edelwis I Citra Indah City Bogor Regency. Required cooperation between women who have toddlers and posyandu cadres in terms of motivating mother to bring toddlers they to posyandu.
\end{abstract}

Keywords: Attitude, Motivation, Community Leader Support, Compliance Behavior. 


\section{PENDAHULUAN}

Posyandu merupakan salah satu upaya yang bersumber daya masyarakat, yang dilaksanakan oleh Kader Kesehatan yang telah mendapatkan pendidikan dan pelatihan. Menurut Kementrian Kesehatan Republik Indonesia (2019), jumlah Posyandu di Indonesia sebanyak 296.777 yang tersebar di seluruh Indonesia. Sebanyak 188.855 atau sekitar 63,6\% Posyandu diantaranya merupakan Posyandu aktif. Posyandu aktif adalah Posyandu yang mampu melaksanakan kegiatan utamanya secara rutin setiap bulan (KIA: ibu hamil, ibu nifas, bayi, balita, KB, imunisasi, gizi, pencegahan dan penanggulangan diare). Keberadaan Posyandu sudah menjadi hal penting di tengah masyarakat karena berfungsi sebagai wadah pemberdayaan masyarakat dalam alih informasi dana keterampilan dari petugas kepada masyarakat. Selain itu, mendekatkan pelayanan kesehatan dasar terutama yang berkaitan dengan penurunan angka kematian ibu (AKI), angka kematian balita (AKBA), dan angka kematian bayi (AKB).

Upaya peningkatan kualitas SDM dimulai dengan proses tumbuh kembang anak sejak pembuahan sampai usia dewasa. Pada masa tumbuh kembang ini, pemenuhan kebutuhan dasar anak seperti perawatan dan makanan bergizi dapat membentuk SDM yang cerdas, sehat dan produktif. Penimbangan balita di Posyandu merupakan indiktaor yang berkaitan dengan cakupan pelayanan gizi pada balita, cakupan imunisasi serta prevalensi gizi kurang (Sugiyarti, dkk., 2014). Posyandu diadakan setiap bulannya dengan sasaran bayi atau balita usia 0-5 tahun guna mengetahui status gizi balita dengan menggunakan buku KIA/ Kartu Menuju Sehat (Ismawati, 2010).

Pada Laporan UNICEF tahun 2019, mengatakan bahwa setidaknya 462.000 anak-anak di dunia menderita gizi kurang. Dalam laporan UNICEF dinyatakan bahwa masalah kesehatan ini terjadi di negara miskin dan menengah. Kondisi ekonomi di masyarakat menjadi masalah pokok. Menurut WHO (2019) diketahui bahwa angka kejadian gizi buruk berakibat 46,7\% kematian bayi dan anak. Berdasarkan hasil sensus WHO sebanyak 49\% kematian balita di negara berkembang berhubungan dengan gizi buruk. Tercatat sebanyak 50\% balita Asia, 30\% balita Afrika, 20\% Amerika Latin menderita gizi buruk (DEPKES, 2013). Selain itu, WHO (2013) mengakui bahwa Posyandu memberikan kontribusi yang besar terhadap keberhasilan penurunan prevalensi masalah gizi kurang menunjukkan penurunan sebesar 18,4\% pada tahun 2011 menjadi sebanyak 13,9\% pada tahun 2013.

Hasil laporan Riskesdas (2018), menyatakan bahwa presentase gizi buruk di Indonesia adalah 3,9\%, sedangkan presentase gizi kurang adalah 13,8\%. Menurut Kementrian Kesehatan pada Profil Kesehatan Indonesia tahun 2019, jumlah Angka Kematian Ibu (AKI) tahun 2018-2019 terdapat penurunan dari 4.226 menjadi 4.221 kematian ibu di Indonesia berdasarkan laporan. 
Sementara angka kematian balita pada tahun 2019 sebanyak 29.332 (69\%) dengan penyebab kematian terbanyak adalah diare yaitu sebanyak 2.092 (71,5\%).

Berdasarkan data yang diperoleh dari Laporan Posyandu Edelwis 1 pada tahun 2017, ada sebanyak 82 ibu yang memiliki balita yang terdaftar di Wilayah Kerja Posyandu Edelwis 1 dan ibu yang melakukan kunjungan rutin ke Posyandu sebanyak 23 orang. Namun pada tahun 2018 mengalami peningkatan pada jumlah ibu yang memiliki balita, yaitu sebanyak 176 orang dengan ibu yang melakukan kunjungan sebanyak 34 orang. sedangkan di tahun 2019, mengalami penurunan pada jumlah ibu yang memiliki balita di Wilayah Kerja Posyandu Edelwis 1, yaitu sebanyak 62 orang dan ibu yang melakukan kunjungan 44 orang.

Berdasarkan hasil studi pendahuluan yang dilakukan peneliti pada tanggal 18 Oktober 2020 dengan mewawancarai 10 responden didapatkan 6 dari responden mengatakan tidak sempat dan lupa pada jadwal Posyandu dikarenakan banyaknya kegiatan, sedangkan 4 lainnya mengatakan tidak ada yang mengantar, bekerja dan sedang berpergian sehingga tidak dapat mengikuti kunjungan jadwal Posyandu. Tujuan penelitian ini adalah mengetahui mengetahui hubungan sikap, motivasi dan dukungan tokoh masyarakat terhadap perilaku kepatuhan ibu dalam membawa balita ke Posyandu Edelwis I Citra Indah City Kabupaten Bogor tahun 2020.

\section{METODE}

Penelitian ini merupakan penelitian kuantitatif dengan desain studi cross sectional. Populasi dari penelitian ini adalah seluruh ibu yang memiliki balita yaitu sebanyak 50 orang, sampel penelitian ini berjumlah 50 orang responden dengan teknik pengambilan sampel menggunakan total sampling. Penelitian ini berlokasi di Posyandu Edelwis I Citra Indah City Kabupaten Bogor. Pengambilan sampel dilakukan pada bulan Oktober - Desember 2020. Analisis data dilakukan secara univariat, analisis ini digunakan untuk mendapatkan gambaran distribusi frekuensi atau besarnya proporsi menurut berbagai karakteristik yang diteliti yaitu variabel independen dan variabel dependen. Analisis data bivariat, analisis ini digunakan untuk melihat hubungan antara 2 variabel, yaitu variabel independen dan variabel dependen. Digunakan uji Chi-Square karena data pada variabel independen dan variabel dependen merupakan data katagorik.

\section{HASIL DAN PEMBAHASAN}

\section{Analisis Univariat}

Pada Tabel 1, variabel yang diteliti menunjukan bahwa sebagian besar ibu yang memiliki balita patuh dalam membawa balita mereka ke Posyandu sebanyak 31 responden (62\%). Sikap positif 
ibu terhadap Posyandu sebanyak 30 responden (60\%). Sedangkan tidak ada dukungan tokoh masyarakat sebanyak 38 responden (76\%). Motivasi ibu dalam membawa balita ke Posyandu sebanyak 25 responden (50\%) memiliki motivasi yang tinggi dan 25 responden (50\%) memiliki motivasi rendah.

Tabel 1.

Distribusi Frekuensi Perilaku Kepatuhan Ibu, Sikap, Motivasi dan Dukungan Tokoh Masyarakat

\begin{tabular}{lcc}
\hline \multicolumn{1}{c}{ Variabel } & Frekuensi (n) & Persentase (\%) \\
\hline Perilaku Kepatuhan Ibu & 19 & 38.0 \\
$\quad$ Tidak Patuh & 31 & 62.0 \\
$\quad$ Patuh & & \\
Sikap Ibu & 20 & 40.0 \\
$\quad$ Negatif & 30 & 60.0 \\
$\quad$ Positif & & \\
Dukungan Tokoh Masyarakat & 38 & 76.0 \\
$\quad$ Tidak Mendukung & 12 & 24.0 \\
$\quad$ Mendukung & & \\
Motivasi Ibu & 25 & 50.0 \\
$\quad$ Rendah & 25 & 50.0 \\
$\quad$ Tinggi &
\end{tabular}

Sumber: Hasil oleh data system komputerisasi tahun 2020

\section{Analisis Bivariat}

Pada Tabel 2, menunjukan bahwa terdapat hubungan sikap terhadap perilaku kepatuhan ibu dalam membawa balita ke Posyandu Edelwis I Citra Indah City Kabupaten Bogor (PValue=0,012; OR=0,808). Serta tidak ada hubungan motivasi (P-Value=0,560) dan dukungan tokoh masyarakat $(0,127)$ terhadap perilaku kepatuhan ibu dalam membawa balita ke Posyandu Edelwis I Citra Indah City Kabupaten Bogor tahun 2020.

Tabel 2.

Hubungan Sikap, Motivasi dan Dukungan Tokoh Masyarakat Terhadap Perilaku Kepatuhan Ibu dalam Membawa Balita Ke Posyandu

\begin{tabular}{|c|c|c|c|c|c|}
\hline \multirow{2}{*}{ Variabel } & \multicolumn{2}{|c|}{ Perilaku Kepatuhan Ibu } & \multirow{2}{*}{ Total } & \multirow{2}{*}{ P Value } & \multirow{2}{*}{ OR } \\
\hline & Tidak Patuh & Patuh & & & \\
\hline \multicolumn{6}{|l|}{ Sikap Ibu } \\
\hline Negatif & $7(35 \%)$ & $13(65 \%)$ & $20(100 \%)$ & 0,012 & 0,808 \\
\hline Positif & $12(40 \%)$ & $18(60 \%)$ & $30(100 \%)$ & & $(250-2,612)$ \\
\hline \multicolumn{6}{|l|}{ Dukungan Tokoh } \\
\hline \multicolumn{6}{|l|}{ Masyarakat } \\
\hline Tidak Mendukung & $6(25 \%)$ & $18(75 \%)$ & $24(100 \%)$ & 0,127 & 0,333 \\
\hline Mendukung & $13(50 \%)$ & $13(50 \%)$ & $26(100 \%)$ & & $(1,00-1,109)$ \\
\hline \multicolumn{6}{|l|}{ Motivasi Ibu } \\
\hline Rendah & $11(44 \%)$ & $14(56 \%)$ & $25(100 \%)$ & & \\
\hline Tinggi & $8(32 \%)$ & $17(68 \%)$ & $25(100 \%)$ & 0,560 & $\begin{array}{c}1,670 \\
(527-5,290)\end{array}$ \\
\hline
\end{tabular}

Sumber: Hasil oleh data system komputerisasi tahun 2020 


\section{Pembahasan}

\section{Hubungan Sikap Terhadap Perilaku Kepatuhan Ibu Dalam Membawa Balita Ke Posyandu di Posyandu Edelwis I Citra Indah City Kabupaten Bogor Tahun 2020}

Berdasarkan hasil bivariat, hubungan sikap terhadap perilaku kepatuhan ibu dalam membawa balita ke Posyandu diperoleh hasil bahwa dari 50 responden dengan sikap positif, terdapat 18 responden $(60 \%)$ berperilaku patuh dalam membawa balita ke Posyandu sedangkan sebanyak 7 responden (35\%) dengan sikap negative dan berperilaku tidak patuh dalam membawa balita ke Posyandu. Dari hasil uji statistic Chi-square, diperoleh nilai $\mathrm{P}$-Value $=0,012$ atau $\mathrm{P} \leq 0,05$, artinya ada hubungan bermakna antara sikap terhadap perilaku kepatuhan ibu dalam membawa balita ke Posyandu. Dari hasil tabulasi nilai $\mathrm{OR}=0,808$ yang secara statistik dapat diartikan bahwa responden dengan sikap positif mempunyai peluang 0,808 kali untuk berperilaku patuh dalam membawa balita mereka ke Posyandu dibandingkan dengan responden yang memiliki sikap negatif. Penelitian ini, sejalan dengan Muharyani (2019), menyatakan adanya hubungan antara sikap dengan perilaku kepatuhan ibu dalam membawa balita ke Posyandu dengan nilai $\mathrm{P}$-value $=0,007$ atau $\mathrm{P}<0,05$, hal ini terjadi karena responden kurang menyadari pentingnya pelaksanaan Posyandu untuk mengetahui kesehatan anak balita. Selain itu, pengetahuan menjadi hal yang bepengaruh dalam sikap responden terhadap pelaksanaan Posyandu, banyak responden yang masih kurang mengetahui pentingnya program Posyandu untuk pertumbuhan anak balitanya, kurangnya motivasi responden untuk berkunjung ke Posyandu, kualitas pelayanan kader yang rendah menjadi alasan mengapa banyak ibu yang tidak membawa anak balitanya ke Posyandu. Demikian juga dengan penelitian yang dilakukan oleh Suryaningsih (2012), menyatakan adanya hubungan antara sikap dengan perilaku kunjungan balita ke Posyandu, dengan nilai $\mathrm{P}$-value $=0,011$ atau $\mathrm{P}<0,05$ dan menurut hasil penelitian yang dilakukan oleh Triwahyudianingsih (2009), menyatakan adanya hubungan antara sikap ibu balita dengan perilaku kepatuhan ibu dalam membawa anak balitanya ke Posyandu dengan nilai $\mathrm{P}$-value $=0,009$ atau $\mathrm{P} \leq 0,05$. Selain itu, hasil penelitian yang dilakukan oleh Pristiani, dkk (2016), juga menyatakan adanya hubungan antara sikap dengan perilaku kepatuhan kunjungan ibu balita ke Posyandu, dengan nilai $\mathrm{P}-$ value $=0,025$ atau $\mathrm{P} \leq 0,05$.

Menurut Notoadmodjo (2012), sikap merupakan reaksi atau respons yang masih tertutup dari seseorang terhadap suatu stimulus atau objek. Sikap adalah evaluasi atau reaksi perasaan, sikap seseorang terhadap suatu objek adalah perasaan mendukung atau memihak maupun perasaan tidak mendukung atau tidak memihak pada objek tersebut (Azwar, 2013).

Berdasarkan hasil penelitian ini, terdapat hubungan antara sikap terhadap perilaku kepatuhan ibu dalam membawa balita ke Posyandu. Peneliti berasumsi bahwa sikap responden yang 
positif akan membuat ibu berperilaku patuh dan mau membawa balita mereka ke Posyandu. Hal ini sesuai dengan teori bahwa sikap seseorang terhadap objek adalah perasaan mendukung atau memihak terhadap objek tersebut (Azwar, 2013).

\section{Hubungan Motivasi Terhadap Perilaku Kepatuhan Ibu Dalam Membawa Balita Ke Posyandu Di Posyandu Edelwis I Citra Indah City Kabupaten Bogor Tahun 2020}

Berdasarkan hasil analisis bivariat, menunjukan hubungan antara motivasi terhadap perilaku kepatuhan ibu dalam membawa balita ke Posyandu, diperoleh hasil diantara 50 responden dengan ibu yang memiliki motivasi rendah, terdapat sebanyak 11 responden (44\%) dengan perilaku tidak patuh dalam membawa balita ke Posyandu. Sedangkan ibu yang memiliki motivasi tinggi, terdapat 17 responden (68\%) dengan perilaku patuh membawa anak balita ke Posyandu. Dari hasil uji statistic Chi-square,diperoleh nilai $\mathrm{P}$-Value $=0,560$ atau $\mathrm{P} \geq 0,05$, artinya tidak ada hubungan bermakna antara motivasi terhadap perilaku kepatuhan ibu dalam membawa balita ke Posyandu.

Penelitian ini sejalan dengan yang dilakukan oleh Permatasari (2018), menyatakan tidak ada hubungan antara motivasi dengan perilaku kehadiran ibu membawa balita ke Posyandu, dengan nilai $\mathrm{P}$-value $=0,290$ atau $\mathrm{P} \geq 0,05$. Demikian pada penelitian yang dilakukan oleh Azmi (2016), menyatakan tidak ada hubungan antara motivasi dengan kunjungan ibu balita ke Posyandu, dengan nilai $\mathrm{P}$-value $=0,320$ atau $\mathrm{P} \geq 0,05$ dan penelitian yang dilakukan oleh Suryaningsih (2012), menyatakan tidak ada hubungan antara motivasi dengan perilaku kunjungan ibu balita di Posyandu, dengan nilai $\mathrm{P}$-value $=0,279$ atau $\mathrm{P} \geq 0,05$.

Tetapi penelitian ini berbanding terbalik dengan Senewe, dkk (2016), menyatakan ada hubungan antara motivasi ibu dengan kepatuhan ibu dalam menimbang anak balita, dengan nilai $\mathrm{P}$-value $=0,003$ atau $\mathrm{P} \geq 0,05$ dan penelitian yang dilakukan oleh Nurdin, dkk (2017), menyatakan ada hubungan antara motivasi dengan partisipasi ibu balita ke Posyandu, dengan nilai $\mathrm{P}$-value $=0,003$ atau $\mathrm{P} \geq 0,05$.

Menurut Asnawi (2007), motivasi adalah suatu konsep yang digunakan ketika dalam diri muncul keinginan (intitate) dan menggerakkan serta mengarahkan tingkat tingkah laku. Semakin tinggi motivasi, semakin tinggi intensitas perilakunya. Kunci keberhasilan pelaksanaan Posyandu adalah tumbuhnya partisipasi pada masyarakat (Syafrudin, 2009).

Responden di Posyandu Edelwis I Citra Indah City Kabupaten Bogor, mayoritas memiliki perilaku patuh dengan motivasi tinggi, hal ini karena responden memiliki motivasi intrinsik atau motivasi dari dalam dirinya yang mendorong untuk membawa anak balitanya ke Posyandu, sehingga tahu pertumbuhan anak mereka, dan motivasi ekstrinsik yang dimiliki oleh responden yaitu berupa ajakan dari kader melalui Grup Whatsapp yang dimana para kader ada di dalamnya 
untuk menyebarluaskan informasi atau jadwal seputar Posyandu. Tidak hanya itu, pihak Puskesmas dan pihak desa (Kepala Desa) setempat secara berkala melakukan refresh kader guna meningkatkan pengetahuan kader dan memberikan reward kader yang aktif sehingga bisa menjadi motivasi kader untuk lebih aktif meningkatkan motivasi ibu agar mau berkunjung ke Posyandu.

Walaupun mayoritas responden memiliki motivasi tinggi, namun masih ada beberapa responden yang cenderung mengabaikan pentingnya pelaksanaan Posyandu dengan tidak patuhnya responden membawa anak balita mereka ke Posyandu, hal ini karena mereka lupa dengan jadwal Posyandu yang sudah disebarkan melalui Grup Whatsapp, berpergian masih menjadi alasan mengapa responden tidak hadir dalam pelaksanaan jadwal Posyandu, tidak ada yang mengantar pun menjadi alasan mereka tidak berkunjung untuk menimbangkan anak mereka ke Posyandu. Biasanya responden yang tidak hadir pada saat pelaksanaan Posyandu akan membawa anaknya ke Puskesmas atau Rumah Sakit untuk ditimbang atau imunisasi. Untuk mengoptimalkan pelaksanaan program Posyandu, perilaku ini harus terus ditingkatkan dengan cara lebih aktifnya para kader dan petugas kesehatan untuk mengajak para ibu balita agar mau berkunjung ke Posyandu.

\section{Hubungan Dukungan Tokoh Masyarakat Terhadap Perilaku Kepatuhan Ibu Dalam Membawa Balita Ke Posyandu di Posyandu Edelwis I Citra Indah City Kabupaten Bogor Tahun 2020}

Berdasarkan hasil analisi bivariat, hubungan antara dukungan tokoh masyarakat terhadap perilaku kepatuhan ibu dalam membawa balita ke Posyandu sebanyak 13 responden (50\%) ada dukungan dari tokoh masyarakat dan berperilaku patuh dalam membawa balita ke Posyandu. Sedangkan 6 responden (25\%) tidak ada dukungan dari tokoh masyarakat dan berperilaku tidak patuh dalam membawa balita ke Posyandu. Dari hasil uji statistic Chi-square, diperoleh nilai PValue $=0,127$ atau $\mathrm{P} \geq 0,05$, artinya tidak ada hubungan bermakna antara dukungan tokoh masyarakat terhadap perilaku kepatuhan ibu dalam membawa balita ke Posyandu.

Penelitian ini, sejalan dengan Sutarni (2018), menyatakan tidak ada hubungan antara dukungan tokoh masyarakat dengan partisipasi kepatuhan ibu ke Posyandu, dengan nilai P-value = 1,542 atau $P \geq 0,05$ dan penelitian yang dilakukan oleh Suryaningsih (2012), menyatakan tidak ada hubungan antara dukungan tokoh masyarakat dengan perilaku kunjungan ibu balita ke Posyandu, dengan nilai $\mathrm{P}$-value $=0,228$ atau $\mathrm{P} \geq 0,05$.

Tetapi, hasil penelitian ini berbanding terbalik dengan Hasanah (2015), menyatakan ada hubungan antara dukungan tokoh masyarakat dengan perilaku ibu balita dalam menimbang anaknya ke Posyandu, dengan nilai $\mathrm{P}$-value $=0,006$ atau $\mathrm{P} \leq 0,05$. Adapun hasil penelitian yang 
dilakukan oleh Muharyani (2019), menyatakan ada hubungan antara dukungan tokoh masyarakat dengan kepatuhan ibu dalam membawa anak balita ke Posyandu, dengan nilai Pvalue $=0,000$ atau $\mathrm{P} \leq 0,05$ dan hasil penelitian yang dilakukan oleh Noeralim, dkk (2017), menyatakan adanya hubungan antara dukungan tokoh masyarakat dengan perilaku keaktifan kunjungan ibu balita ke Posyandu, dengan nilai $\mathrm{P}$-value $=0,004$ atau $\mathrm{P} \leq 0,05$.

Menurut Tricia (2008) dalam Suryaningsih (2012), keterlibatan informal dan partisipasi organisasi masyarakat akan berpengaruh terhadap keberhasilan program Posyandu. Kegiatan Posyandu dilakukan oleh masyarakat dan untuk masyarakat itu sendiri. Oleh karena itu, jika tokoh masyarakat tersebut tidak berpartisipasi ataupun terlibat dalam kegiatan Posyandu ada kemungkinan bahwa masyarakat setempat tidak akan menggunakan Posyandu.

Responden yang merasa mendapat dukungan dari tokoh masyarakat dan memiliki perilaku yang patuh lebih banyak dibandingkan dengan responden yang merasa tidak mendapat dukungan dari tokoh masyarakat dan memiliki perilaku yang tidak patuh. Dukungan tokoh masyarakat berpengaruh pada kelangsungan program Posyandu, dimana para ibu merasa mendapat motivasi ekstrinsik yang baik dari para tokoh masyarakat, perilaku ini harus terus ditingkatkan agar peran penting tokoh masyarakat dalam kelangsungan program Posyandu, membuat kelangsungan program tersebut dapat berjalan dengan optimal.

\section{SIMPULAN DAN REKOMENDASI}

Terdapat hubungan sikap terhadap perilaku kepatuhan ibu dalam membawa balita ke Posyandu ( $\mathrm{p}$-value $=0,012)$. Responden dengan sikap positif mempunyai peluang 0,808 kali untuk berperilaku patuh dalam membawa balita mereka ke Posyandu dibandingkan dengan responden yang memiliki sikap negatif. Serta tidak ada hubungan motivasi (p-value $=0,560$ ) dan dukungan tokoh masyarakat $(\mathrm{p}$-value $=0,127)$ terhadap perilaku kepatuhan ibu dalam membalita ke Posyandu. Upaya yang perlu dilakukan guna meningkatkan angka perilaku kepatuhan ibu dalam membawa balita ke Posyandu adalah dengan meningkatkan pengetahuan ibu melalui sosialisasi oleh pihak Kader Posyandu setempat tentang pentingnya program pelaksanaan Posyandu, manfaat Posyandu dan dampak jika ibu tidak patuh dalam membawa balita mereka ke Posyandu. Perlu ada kerjasama antar pihak Puskesmas dan pihak desa setempat secara berkala melakukan refresh kader guna meningkatkan pengetahuan kader dan memberikan reward kepada kader yang aktif. 


\section{REFERENSI}

1. Asnawi, S. 2007. Teori Motivasi Dalam Pendekatan Psikologi Industri dan Organisasi. Jakarta: Studi Press

2. Azwar S. 2013. Sikap Manusia: Teori dan Pengukurannya. Yogyakarta: Pustaka Pelajar.

3. Hasanah, J I. 2015. Faktor-Faktor Yang Berhubungan Dengan Perilaku Ibu Balita Dalam Menimbang Anaknya Ke Posyandu Di Wilayah Kerja Puskesmas Kelurahan Rorotan Kecamatan Cilincing Jakarta Utara. Skripsi : UIN Syarif Hidayatullah Jakarta.

4. Ismawati, Cahyo, S. 2010. Posyandu dan Desa Siaga, Nuha Medika, Yogyakarta.

5. Kemenkes RI. 2019. Petunjuk Teknis Penyelenggaraan Posyandu. Jakarta: Kemenkes RI.

6. Muharyani, W P. 2019. Determinan Faktor Yang Berhubungan Dengan Kepatuhan Ibu Dalam Membawa Anak Balita Ke Posyandu Di Kelurahan 14 Ulu Palembang. Skripsi : Universitas Sriwijaya.

7. Notoatmodjo, Soekidjo. 2010. Metodologi Penelitian Kesehatan. PT. Rineka Cipta. Jakarta

8. Permatasari, I D L. 2018. Faktor-Faktor Yang Berhubungan Dengan Tingkat Perilaku Kehadiran Ibu Di Posyandu Wilayah Kerja Puskesmas Sangkrah. Skripsi: Universitas Muhammadiyah Surakarta

9. Senewe, dkk. 2016. Analisis Faktor-Faktor Yang Berhubungan Dengan Kepatuhan Ibu Dalam Menimbang Anak Balita Di Wilayah Puskesmas Tongkaina Kecamatan Bunaken Kota Madya Manado. E-Jurnal Keperawatan : Universitas Sam Ratulangi. Volume 5 Nomor 1 Tahun 2017.

10. Sugiyono. 2010. Metode Penelitian Pendidikan Pendekatan Kuantitatif, Kualitatif dan R\&D. Alfabeta. Bandung

11. Suryaningsih, H. 2012. Faktor-Faktor Yang Berhubungan Dengan Perilaku Kunjungan Ibu Bayi dan Balita Ke Posyandu di Puskesmas Kemiri Muka Kota Depok. Skripsi: Universitas Indonesia.

12. UNICEF. 2019. Sekitar 35 Juta Balita Masih Berisiko Jika Target Angka Kematian Anak Tidak Tercapai. Jakarta: UNICEF Indonesia.Universitas Sebelas Maret. Surakarta. $87 \mathrm{pp}$. 